\title{
The Stool Antigen Test is Efficient at Detecting Helicobacter pylori Infection in Bangladeshi Peptic Ulcer Patients
}

\author{
Afreen Sultana ${ }^{1}$, Shakeel Ahmed ${ }^{2}$, Ershad Uddin Ahmed ${ }^{3}$, Abul Faisal MD. Nuruddin Chowdhury ${ }^{4, *}$, \\ Abul Kalam ${ }^{1}$, Arifur Rahman ${ }^{1}$, Farhana Akter ${ }^{5}$, A. H. M. Saiful Karim Chowdhury ${ }^{1}$, Sabrina Sharmin ${ }^{1}$, \\ Jannatul Ferdous Mustry6 ${ }^{6}$, Ayan Saha ${ }^{70}$
}

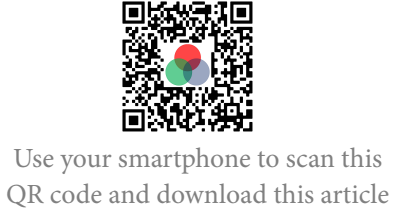

${ }^{l}$ Department of Microbiology and Virology, Chittagong Medical College, Chattogram, Bangladesh

${ }^{2}$ Bangladesh Institute of Tropical and Infectious Diseases (BITID),

Chattogram, Bangladesh

${ }^{3}$ Department of Gastroenterology, Chittagong Medical College, Chattogram, Bangladesh

${ }^{4}$ Department of Medicine, Chittagong Medical College, Chattogram, Bangladesh

${ }^{5}$ Department of Endocrinology, Chittagong Medical College,

Chattogram, Bangladesh

${ }^{6}$ Sheikh Hasina National Institute of Burn and Plastic Surgery, Bangladesh

${ }^{7}$ Department of Genetic Engineering and Biotechnology, East West University, Dhaka, Bangladesh

Correspondence

Abul Faisal MD. Nuruddin Chowdhury, Department of Medicine, Chittagong Medical College, Chattogram, Bangladesh

Email: afmchy07@gmail.com

History

- Received: Nov 21, 2021

- Accepted: Feb 04, 2022

- Published: Feb 16, 2022

DOI : 10.15419/ajhs.v8i1.501

\section{Check for updates}

\section{Copyright}

(c) Biomedpress. This is an openaccess article distributed under the terms of the Creative Commons Attribution 4.0 International license.

\begin{abstract}
Aims: Helicobacter pylori (H. pylori) is the primary causative agent of peptic ulcers in multiple developing countries, including Bangladesh. This study was designed to investigate the diagnostic value of a rapid immunochromatography-based $H$. pylori stool antigen (HpSAg) test to screen for H. pylori infection in a Bangladeshi population. Methodology and results: A total of 140 suspected peptic ulcer patients who underwent an upper gastrointestinal endoscopy at Chittagong Medical College and Hospital, Chattogram, Bangladesh were included in the study. A histopathology, rapid urease test (RUT), and microscopic examination of the stained smears were conducted to define the H. pylori-positive cases. Later, a stool antigen detection test was performed for the H. pylori-positive status group, the H. pylori-negative status group, the indeterminate status group, and the healthy controls. Out of the 140 suspected peptic ulcer patients, 75 (53.6\%) patients were confirmed to have peptic ulcers or erosions. Although the proportion of antral erosion was $57.4 \%$ in patients who were under 40 years old, it decreased to $23.4 \%$ in patients over 40 years old. Patients over 40 years of age mostly suffered from pyloric erosion (42.9\%). All peptic ulcer patients were also positive according to the histopathological analysis. However, microscopic grading of the curved bacilli and RUT were found among 93.3\% (70/75) and 89.3\% (67/75) patients who were positive, respectively. In our study, high sensitivity (95\%), specificity (80\%), and diagnostic accuracy (91\%) scores for the HpSAg assay were obtained. Conclusions, significance, and impact of the studies: The HpSAg test, as a comparatively less sophisticated assay, can be efficient at detecting the presence of $H$. pylori pre- and post-therapy, and it provides more valid test results than other invasive test methods.
\end{abstract}

Key words: antigen, Bangladesh, diagnosis, dyspepsia, Helicobacter pylori

\section{INTRODUCTION}

Helicobacter pylori (H. pylori) is a well-defined, spiralshaped, gram-negative bacterium that is the primary causative agent of several gastric pathologies ranging from mild gastritis to gastric malignancies ${ }^{1}$. Infection with $H$. pylori causes the chronic inflammation of the gastric mucosa and significantly increases the risk of developing duodenal and gastric ulcers as well as gastric cancer. The prevalence of infection varies widely depending on geography, age, race, ethnicity, and socioeconomic status. In developing countries, the rates appear to be greater than in developed countries with the majority of infections occurring during childhood. The prevalence among middle-aged adults is over $80 \%$ in many developing countries compared to $20 \%$ to $50 \%$ in industrialized countries ${ }^{2}$.

Similar to other developing countries, the rate of $H$. pylori infection is notably high in Bangladesh. In 1997, Ahmad et al. reported that the prevalence of
H. pylori infection in Bangladesh was $92 \%$ in their serology-based study ${ }^{3}$. Mahalanabis et al., in a study based on the 13C-urea breath test, also reported that the prevalence of $H$. pylori was $84 \%$ in children aged 69 years old ${ }^{4}$. The overall $H$. pylori prevalence in other Asian countries, including India (79\% by ELISA) and Pakistan ( $84 \%$ by PCR), was also reported to be high $^{3,5}$. A significantly lower prevalence rate of $H$. pylori was observed in Europe (40\%) and the United States $(40 \%)^{6,7}$. High infection rates in developing countries may be the consequence of poor socioeconomic conditions and unhygienic lifestyles ${ }^{8}$.

The association between $H$. pylori and gastroduodenal diseases necessitates the proper and timely diagnosis of infection in dyspeptic patients. Serology is quick, relatively inexpensive, and has good sensitivity. However, anti-H. pylori IgG can usually be detected by 3 4 weeks after infection. This is a drawback since this mode of testing is ineffective at detecting the presence of $H$. pylori during an earlier stage of pathogenesis ${ }^{9}$. 
Hence, the serology test results can be misleading and serve as false positive test results, which could be invalid $^{10}$. The urea breath test provides a reliable, noninvasive method for the detection of $H$. pylori infection. It has a high accuracy and reproducibility with a sensitivity and specificity of $90-96 \%$ and $88-98 \%$, respectively ${ }^{11}$. Nevertheless, it is relatively expensive and requires mass spectrometric analysis, which may not be available in limited resource centers ${ }^{12}$.

$H$. pylori also appears in stool as it is a gastrointestinal pathogen. Stool tests have the advantage of being non-invasive, and the specimen is easily obtainable. The monoclonal antibody-based $H$. pylori stool antigen (HpSAg) assay has been clinically useful with a sensitivity and specificity of more than $90 \%$. The specimen is easily obtainable and can be used as a routine diagnostic tool for $H$. pylori infection because it seems to overcome the limitations of conventional invasive techniques ${ }^{3,13}$. The detection of $H$. pylori antigens in fecal samples may be useful for the non-invasive diagnosis of infection in both children and adults, selecting cases requiring endoscopic examination and in epidemiological studies ${ }^{14}$.

The present study was designed to analyze the diagnostic value of a rapid immunochromatographybased stool antigen test compared to invasive tests - like the rapid urease test and the histopathological analysis of a gastric mucosal biopsy - to diagnose H. pylori infection in adult patients with peptic ulcer disease before treatment. For a developing country such as Bangladesh, the accessibility and reliability of rapid immunochromatography-based stool antigen tests can be useful in the quicker detection of $H$. $p y$ lori infection, when obtaining valid results during and post infection, when overcoming the economic and technical barriers of other biochemical assays, and when facilitating proper disease management.

\section{MATERIALS AND METHODS}

\section{Sample collection}

A cross-sectional descriptive study was conducted in the Department of Microbiology, Department of Pathology and Department of Gastroenterology, Chattogram Medical College and Hospital (CMCH), Chattogram over the period from July 2018 to June 2020 involving a total of 140 patients with suspected peptic ulcer disease and 20 asymptomatic individuals of either sex, aged from 18 to 70 years old. To study a representative sample of the healthy population with an active infection, stool samples from 20 healthy individuals were included in this group for the HpSAg test. A structured questionnaire was developed to collect the data from the patients. Every ethical issue was discussed with the patients regarding the study, and informed written consent was subsequently obtained. Patients with symptoms related to the upper GI tract and the symptoms of peptic ulcer disease (PUD) (burning epigastric pain exacerbated by fasting and improved with meals, anorexia, nausea, vomiting, bloating, belching, etc.), diagnosed clinically, advised by physicians to undergo an endoscopic examination, and subsequently diagnosed with gastritis and peptic ulcers through endoscopic findings, were included in this study.

\section{Collection of and experiments on the spec- imens}

\section{Gastric biopsy}

Expert endoscopists performed upper GI endoscopies on selected patients in the Department of Gastroenterology, $\mathrm{CMCH}$, with the aim of detecting peptic ulcer disease. A total of 140 patients who fulfilled the inclusion criteria and attended the gastroenterology outpatient department were initially enrolled for an upper GI endoscopy. The study eventually comprised 75 participants who had endoscopic signs of peptic ulcer disease. Biopsy specimens were sampled from both the gastric antrum and the corpus. Three biopsy tissues were obtained from the gastric antrum and one from the upper corpus of the stomach of each patient. Two biopsy specimens of the antrum and one of the corpus were fixed in $10 \%$ buffered formalin for the histopathology. The other biopsy specimen from the antrum was incubated in a rapid urease test (RUT) kit, and the results were recorded on the data sheet.

\section{Laboratory procedures}

The RUT was performed instantly on one antral biopsy specimen using a commercially available kit, Pronto Dry. The results were available within a few minutes to a few hours, always within 24 hours ${ }^{15}$. A histopathological examination was performed on both the antrum and gastric corpus biopsy samples. The biopsy specimens for the histopathology were processed according to the standard procedure.

\section{Immunochromatographic test (ICT) of the stool for $\mathrm{H}$. pylori antigen}

The patients were asked to collect a specimen from their first stool sample after an endoscopy. The HpSAg test was performed on 75 patients and 20 healthy controls. In the test cassette, there is a membrane precoated with monoclonal anti-H. pylori antibody on the test line region of the cassette (Acro, Biotech Inc., 
California, USA). During the test, the specimen reacts with the latex particles coated with antibody. The mixture migrates upward by capillary action to react with the anti-H. pylori antibody on the membrane, generating a colored line. The presence of this colored line in the test region indicates a positive result, and its absence indicates a negative result. Any shade of color in the test line region will be considered positive.

\section{Data analysis}

All relevant medical history, physical examination records, clinical findings, and laboratory records of every subject were systematically added to a predesigned datasheet for subsequent analysis. The continuous variables were reported as the mean $\pm \mathrm{SD}$, and the categorical variables were reported as percentages. The two tests for the categorical data were used to compare the baseline characteristics. The statistical significance was defined as $\mathrm{p}<0.05$, and the confidence interval was set at the $95 \%$ level. The SPSS (Statistical Package for Social Science) version 20 software was used for the analyses.

\section{RESULTS}

\section{Clinical characteristics of the patients}

Table 1 represents the age distribution of the patients with dyspepsia based on the endoscopic diagnosis. Among the 140 patients, 77 (55.0\%) were in the 21to 40 -year-old age group, 48 (34.3\%) belonged to the 41 - to 60 -year-old age group, $11(7.8 \%)$ were in the age group above 60 years, and four (2.9\%) were in the age group below 20 years old. The endoscopic diagnosis revealed that most of the patients (55.0\%) with dyspepsia were in the age group of 21 to 40 years, followed by 48 (34.3\%) in the age group of 41 to 60 below 20 years. The mean age of the patients was $39.4 \pm 11.4$ years. There were $76(54.3 \%)$ male participants and $64(45.7 \%)$ female participants in the study. The male:female ratio was 1.06:1, and no correlation was observed between the endoscopic findings and the sex of the patients. Among the different categories of peptic ulcer, antral erosion (25.7\%) and prepyloric erosion (15.0\%) were more prevalent (Figure 1A) (Supplementary Figure 1). The proportion of antral erosion was $57.4 \%$ in patients who were younger than 40 years old. This particular type of ulcer decreased to $23.4 \%$ in patients over 40 years. Patients over 40 years of age mostly suffered from pyloric erosion (42.9\%) (Figure 1 B). The percentage of reflux esophagitis in non-ulcer patients over 40 years of age increased by approximately $10 \%$ compared to those under 40 years of age (Figure $\mathbf{1 ~ C )}$ ).

\section{Different $\boldsymbol{H}$. pylori detection approaches to} define $\boldsymbol{H}$. pylori-positive patients

The comparative results of all four techniques unitized in this study to detect $H$. pylori have been illustrated in Figure 2. The histopathological grading of chronic gastritis identified the presence of $H$. pylori in a total of 75 patients. However, the microscopic grading of the curved bacilli of $H$. pylori was identified in 70 patients. Among these 70 patients, 67 were $H$. pylori positive in the rapid urease test (RUT), and 65 were $H$. pylori positive in the HpSAg test.

Figure $3 \mathbf{A}$ shows the histopathological grading of chronic gastritis. Out of 75 patients, 59 (78.0\%) had mild inflammation, 14 (18.7\%) had moderate inflammation, and 2 (2.7\%) had chronic active gastritis. Figure $3 \mathbf{B}$ shows the bacterial density and severity of gastritis among the studied subjects. The highest percentage of patients was in grade $2(44.0 \%)$, and the next highest was in the grade 1 group $(36.0 \%)$. The rest of the patients who were found to have bacilli were in group 3 (13.3\%). Bacilli were found in a total of 70 (93.3\%) cases. Figure $3 \mathrm{C}$ and Table 2 show the rapid urease test (RUT) results in endoscopically proven ulcer and erosion cases. Among the 75 patients, 67 (89.3\%) were RUT positive, and 8 (10.7\%) were RUT negative.

Table 2 depicts the relationship between bacterial density and gastritis severity. Out of the 59 cases with mild inflammation, the bacterial density was as follows: 25 patients showed grade -1 bacterial load, 23 had grade $-2,6$ patients showed grade -3 load, but no bacilli were seen in 5 cases. Among the 14 moderate inflammation cases, 2 had grade - 1, 9 had grade 2 , and 3 had grade -3 bacterial loads. Among the two cases of chronic active inflammation, 1 showed grade -2 and 1 showed grade -3 bacterial density. Interestingly, among the eight RUT-negative patients, three had grade 1 microscopic curved bacilli (Table 2).

Figure $3 \mathrm{D}$ shows the combined result of the RUT and microscopic grading detection (MD) of curved bacilli and the H. pylori status of the patient. According to the definition of the gold standard, both invasive test positive cases were considered to be $H$. pyloripositive states, and both invasive test negative cases were considered $H$. pylori-negative states. Any one of the test's positive cases was considered to be indeterminate. Out of the 75 cases, 67 were $H$. pylori-positive, 5 were $H$. pylori-negative, and 3 were indeterminate. Either RUT or MD positivity, but not both positivity, were defined as an indeterminate state. All three indeterminate cases were MD positive but RUT negative. 
Table 1: Association of $\boldsymbol{H}$. pylori infection prevalence with age and gender

\begin{tabular}{|c|c|c|c|c|c|}
\hline Characteristics & $N=140(\%)$ & $\begin{array}{l}\text { Ulcer \& erosion; } \\
n=75(53.6 \%)\end{array}$ & $\begin{array}{l}\text { No ulcer/erosion; } \\
\mathrm{n}=65(46.4 \%)\end{array}$ & Chi-square & P-value \\
\hline \multicolumn{6}{|c|}{ Age $($ years); Mean age $=39.4 \pm 11.4(\mathrm{SD})$} \\
\hline$<20$ & $4(2.9 \%)$ & $2(50.0 \%)$ & $2(50.0 \%)$ & 15.4 & 0.0015 \\
\hline $21-40$ & $77(55.0 \%)$ & $52(67.5 \%)$ & $25(32.5 \%)$ & & \\
\hline $41-60$ & $48(34.3 \%)$ & $19(39.6 \%)$ & $29(60.4 \%)$ & & \\
\hline$>60$ & $11(7.8 \%)$ & $2(18.2 \%)$ & $9(81.8 \%)$ & & \\
\hline \multicolumn{6}{|c|}{ Gender; male: female ratio of $1.06: 1$} \\
\hline Male & $76(54.3 \%)$ & $43(56.6 \%)$ & $33(43.4 \%)$ & 0.6 & 0.4368 \\
\hline Female & $64(45.7 \%)$ & $32(50.0 \%)$ & $32(50.0 \%)$ & & \\
\hline
\end{tabular}

(A)

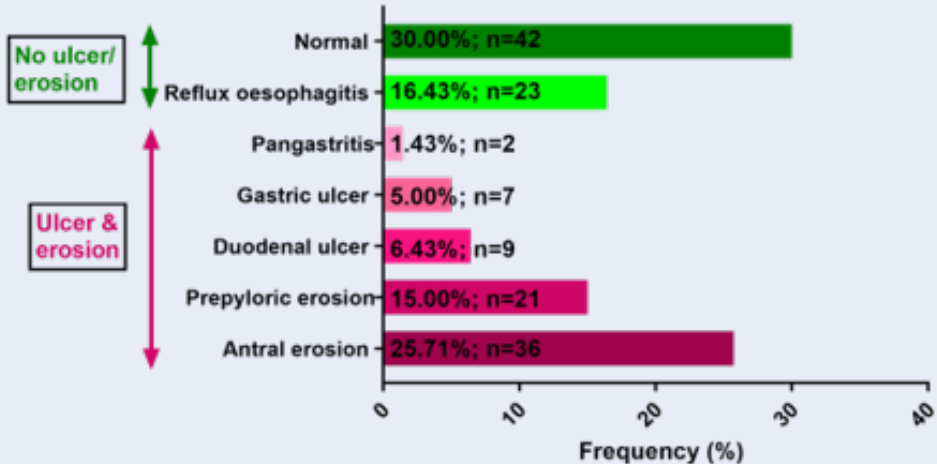

(B)

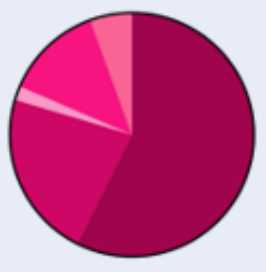

Age $\leq 40$ years; $n=54$

(C)

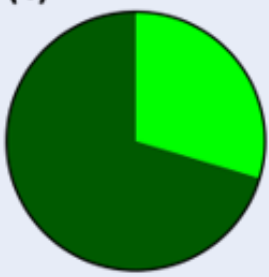

Age $\leq 40$ years; $n=27$
- $57.41 \%$ Antral erosion; $n=31$ $=22.22 \%$ Prepyloric erosion; $n=12$ - $12.96 \%$ Duodenal ulcer, $n=7$ - $5.56 \%$ Gastric ulcer, $n=3$

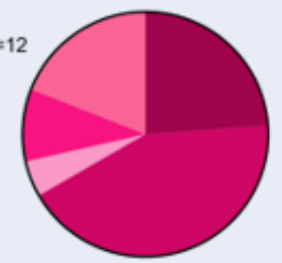

- 23.81\% Antral erosion; $n=5$ - $42.86 \%$ Prepyloric erosion; $n=9$ $4.76 \%$ Pangastritis; $n=1$

9.52\% Duodenal ulcer, $n=2$

$19.05 \%$ Gastric ulcer; $n=4$

Age $>40$ years; $n=21$

- $29.63 \%$ Reflux oesophagitis; $n=8$ - $70.37 \%$ Normal; $n=19$

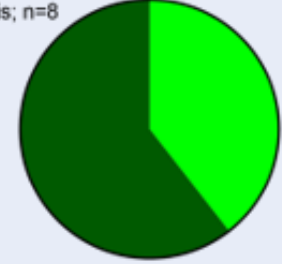

Age $>40$ years; $n=38$

Figure 1: Identification and prevalence of peptic ulcer inpatients with dyspepsia based on endoscopic diagnosis. (A) Prevalence of different types peptic ulcers in the studied patients; (B) Frequency of different type peptic ulcers inpatients below and over 40 years; (C) Frequency of normal and reflux oesophagitis cases in non-peptic ulcer patients below and over 40 years. 


\begin{tabular}{|c|c|c|c|c|}
\hline Test & $\begin{array}{l}\text { Histopathological } \\
\text { grading of chronic } \\
\text { gastritis }\end{array}$ & $\begin{array}{c}\text { Microscopic } \\
\text { grading of curved } \\
\text { bacilli }\end{array}$ & Rapid urease test & Stool Antigen Test \\
\hline $\begin{array}{l}\text { Sample } \\
\text { results }\end{array}$ & & & 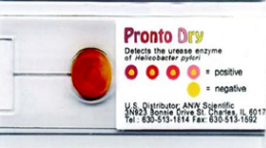 & (อ) \\
\hline Positive & 75 (100\%) & 70 (89.3\%) & 67 (93.3\%) & 65 (86.6\%) \\
\hline Negative & $00(0.0 \%)$ & $05(10.7 \%)$ & $08(6.7 \%)$ & $10(14.4 \%)$ \\
\hline
\end{tabular}

Figure 2: All four procedures were used to identify H. pylori in the studied subjects.

Table 2: Demonstration of curved bacilli on microscopic examination \& its relation to Histopathology and Rapid urease test $[n=75]$

\begin{tabular}{|c|c|c|c|c|c|}
\hline & \multirow[t]{2}{*}{ No. of cases } & \multicolumn{3}{|c|}{ Microscopic grading of curved bacilli } & \multirow{2}{*}{$\begin{array}{c}\text { No Bacilli seen } \\
\text { Grade } 0\end{array}$} \\
\hline & & Grade 1 & Grade 2 & Grade 3 & \\
\hline \multicolumn{6}{|c|}{ Histopathological grading of chronic gastritis } \\
\hline Mild & 59 & 25 & 23 & 6 & 5 \\
\hline Moderate & 14 & 2 & 9 & 3 & 0 \\
\hline Chronic active & 2 & 0 & 1 & 1 & 0 \\
\hline Total & 75 & 27 & 33 & 10 & 5 \\
\hline \multicolumn{6}{|c|}{ Rapid urease test (RUT) } \\
\hline Positive & 67 & 24 & 33 & 10 & 0 \\
\hline Negative & 8 & 3 & 0 & 0 & 5 \\
\hline Total & 75 & 27 & 33 & 10 & 5 \\
\hline
\end{tabular}

Table 3: HpSAg detection results among the $H$. pylori positive \& negative cases $[n=75$ ]

\begin{tabular}{lcccc}
\hline H. pylori status & $\begin{array}{c}\text { Number of } \\
\text { Patients }\end{array}$ & $\begin{array}{c}\text { HpSAg Test } \\
\text { Positive (\%) }\end{array}$ & $\begin{array}{c}\text { HpSAg Test } \\
\text { Negative (\%) }\end{array}$ & Chi $^{2}$ and p-value \\
Positive & 67 & $64(95.5 \%)$ & $3(4.5 \%)$ & $\mathrm{Chi}^{2}=6.47$ \\
Negative & 5 & $0(0.0 \%)$ & $5(100 \%)$ & $\mathrm{p}$-value $=0.041$ \\
Indeterminate & 3 & $1(33.3 \%)$ & $2(66.7 \%)$ & \\
Total & 75 & 65 & 10 & \\
\hline
\end{tabular}

Table 4: Evaluation of HpSAg detection results in $\mathrm{H}$. pylori positive cases \& controls $[n=67+20]$

\begin{tabular}{lcccll}
\hline HpSAg Test & Case & Control & Total & & \\
Positive & 64 & 4 & 68 & Sensitivity of stool ICT & $: 95 \%$ \\
Negative & 3 & 16 & 19 & Specificity of stool ICT & $: 80 \%$ \\
PPV of stool ICTPP & $: 94 \%$ \\
Total & 67 & 20 & 87 & NPV of stool ICTNP & $: 84 \%$ \\
\hline
\end{tabular}

HpSAg: H. pylori stool antigen; ICT: Immunochromatograpic Test; NPV: Negative predictive value; PPV: Positive predictive value 
(A)

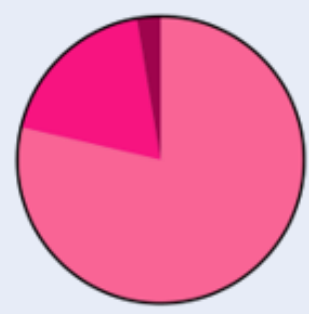

Histopathological grading of chronic gastritis; $\mathbf{n = 7 5}$
78.00\% Mild Inflammatory Activity (Grade=2); $n=59$

$18.66 \%$ Moderate Inflammatory

Activity (Grade=2); $n=14$

$2.66 \%$ Chronic Active Inflammation

(Grade $=3$ ); $n=2$
(B)

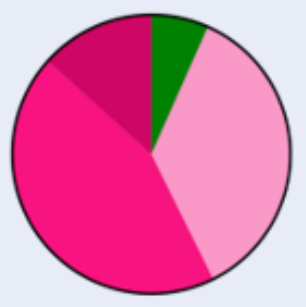

Microscopic grading of curved bacilli, $n=75$
(C)

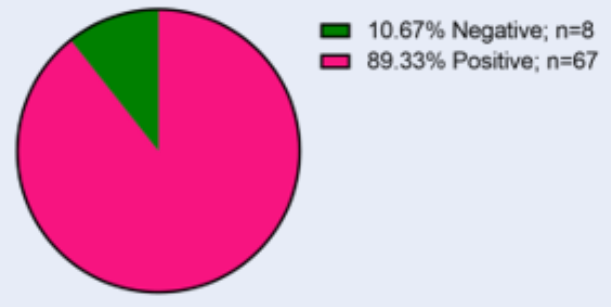

Rapid urease test; $\mathbf{n = 7 5}$

(D)

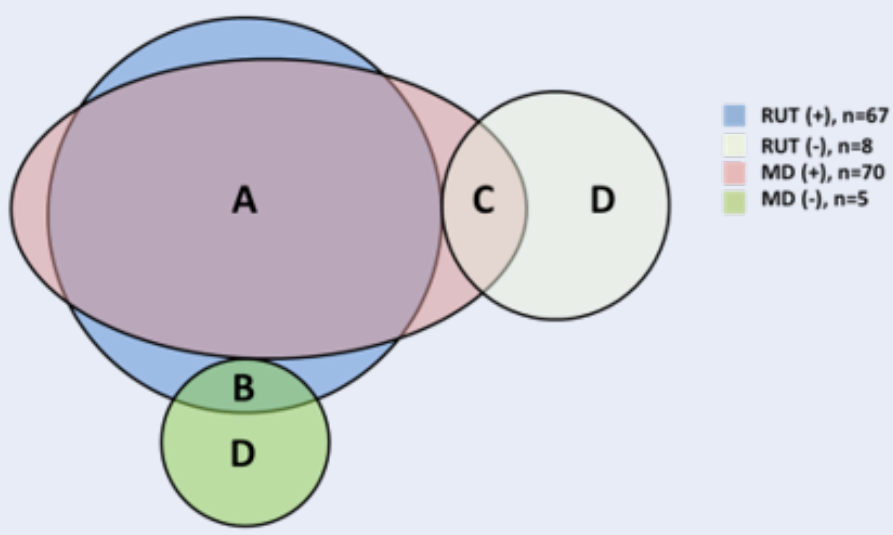

\begin{tabular}{|c|c|c|c|}
\hline Test & Conditions & Number & \\
\cline { 1 - 3 } RUT (+) \& MD (+) & A & $67(89.33 \%)$ & H. Pylori positive \\
\hline RUT (+) \& MD (-) & B & $3(4.00 \%)$ & \multirow{2}{*}{ Indeterminate } \\
\cline { 1 - 3 } RUT (-) \& MD (+) & C & $0(0.00 \%)$ & \multirow{2}{*}{ H. Pylori negative } \\
\hline RUT (-) \& MD (-) & D & $5(6.67 \%)$ & \\
\hline
\end{tabular}

Figure 3: Different approaches to identify H. pylori status in patients. (A) Frequency of histopathological grading of chronic gastritis; (B) Microscopic detection (MD) of curved bacilli in endoscopically proved ulcer and erosion cases; (C) Rapid urease test (RUT) result to identify $H$. pylori positive patients in endoscopically proved ulcer and erosion cases; (D) Comparative result of microscopic detection (MD) and rapid urease test (RUT) to define $H$. pylori positive patients. Either RUT or microscopy positive but not both positive were defined as indeterminate states. Three cases were microscopy positive but RUT negative. 
Sensitivity of the $H$. pylori stool antigen test (HpSAg)

Table 3 represents the stool antigen detection results among the $H$. pylori-positive and $H$. pylori-negative cases. Out of the $67 \mathrm{H}$. pylori-positive cases, 64 (95.5\%) were positive in the HpSAg test. The remaining 3 (4.5\%) cases showed false-negative results. The HpSAg test was negative in all $5(100 \%)$ of the $H$. pylori-negative status patients. No false-positive results were obtained from these patients. Among the three indeterminate cases, $1(33.3 \%)$ was positive for the HpSAg test, and 2 (66.7\%) were negative. A strong association was found between $H$. pylori status and the positivity or negativity of the HpSAg test. $H$. pylori-positive status patients showed more positive HpSAg test results than the H. pylori-negative and indeterminate status groups.

The performance of the HpSAg test is presented in Table 4. To determine the specificity of the HpSAg test, stool samples were collected from 20 healthy individuals with no history of dyspepsia, peptic ulcer disease, and anti-H. pylori therapy in the previous 6 months. Among the 20 healthy controls, $16(80 \%)$ were negative and $4(20 \%)$ positive for the HpSAg test. The study found that the immunochromatographic test for HpSAg detection is highly sensitive and specific with a sensitivity of $95 \%$, specificity of $80 \%$, positive predictive value (PPV) of $94 \%$, negative predictive value (NPV) of $84 \%$, and a diagnostic accuracy of $91 \%$.

\section{DISCUSSION}

In this study, out of the 140 patients with upper GIT symptoms, the highest incidence (55\%) was observed in the 21-40 year age group, followed by the 41-60 year (34.3\%) age group (Table 1 ). The patients' ages ranged from 18 to 70 years, with a mean age of 39.4 years. A similar result was reported by Islam et al. (2010) in Dhaka, Bangladesh, where $60 \%$ of cases were within the $21-40$ year age group, followed by $27 \%$ of cases in the $41-60$ year age group ${ }^{16}$. Overall, the findings of the endoscopy were $30 \%$ normal, $16.4 \%$ reflux esophagitis, $25.7 \%$ antral erosion, $15 \%$ erosion in body and fundus, $5 \%$ gastric ulcers, and $6.43 \%$ duodenal ulcers (Figure $1 \mathbf{A}$ ). These findings are similar to those of Ghosh et al. (2013) in Dhaka, Bangladesh, where among the 72 dyspeptic patients, the gastroduodenal mucosa was normal in 55.6\%. Additionally, there was reflux esophagitis in $8.3 \%$, gastric erosion in $22.2 \%$, gastric ulcers in $2.8 \%$, and duodenal ulcers in $5.7 \%$ of patients ${ }^{17}$. Minor variations can be attributed to the differences in the exclusion and inclusion criteria used in both studies, as well as the socioeconomic level differences, and attitudes about seeking healthcare. In terms of the histopathology, chronic inflammatory infiltrates were seen in almost all patients, with the majority (78\%) showing only mild inflammation (Figure $3 \mathrm{~A}$ ). The density of $H$. pylori colonization increased with the severity of chronic inflammation in this study (Table 2). These findings were compatible with the study performed by Garg et al. (2012) in India, who reported that $70 \%$ of cases had a mild inflammation ${ }^{18}$. A greater density of organisms was noted in higher grades of inflammation. The H. pylori concentration did not affect the activity and overall histological grading of chronic gastritis in their study. This dissimilarity may be due to the genetic differences, nutritional habits, and environmental factors between the two study populations ${ }^{19}$.

Alam et al. (2014) reported an 88.8\% RUT positivity among the PUD patients in Dhaka. These findings are consistent with those of the present study ${ }^{15}$. In contrast to the present study, Islam et al. (2013) reported a lower RUT positivity (61.7\% of patients were RUT positive and $38.3 \%$ were RUT negative). This dissimilarity may be because the sensitivity can vary with the site chosen for the biopsy due to the bacteria's patchy distribution. This means that a false negative test can occur due to sampling errors ${ }^{20}$. In this study, $89.3 \%(67 / 75)$ of the cases were rapid urease tested and histopathologically positive for $H$. $p y$ lori (Figure $3 \mathrm{C}$ ). This is in accordance with the studies performed by Islam et al. (2010) and Alam et al. (2014) in Bangladesh, who reported that $79.0 \%$ and $87.6 \%$ of cases were infected by $H$. pylori, respectively, using the same definition ${ }^{15,16}$. In contrast, Korkmaz et al. (2015) found there to be a lower detection rate of $H$. pylori-positive cases (50.6\%) in Turkey ${ }^{21}$. The higher detection rate is not abnormal, as the study was conducted in a developing country where $80 \%-90 \%$ of the population is estimated to be a carrier of this pathogen. The lower detection rate in the above study was probably due to the study being performed in a developed country.

Our study's most important finding was that the new HpSAg test showed excellent sensitivity and specificity. The sensitivity, specificity, PPV, NPV, and diagnostic accuracy of the HpSAg test were 95\%, $80 \%$, $94 \%, 84 \%$, and $91 \%$, respectively (Table 4 ). Several studies on monoclonal stool antigen tests based on the immunochromatography in various regions of the world have shown comparable results. A similar study performed in Malaysia showed a sensitivity, specificity, PPV, NPV, and accuracy of $91.7 \%, 100 \%, 100 \%$, $94.6 \%$, and $96.6 \%$, respectively ${ }^{22}$. In addition, a study performed in Korea found the sensitivity, specificity, 
PPV, NPV, and accuracy of the H. pylori stool immunochromatographic antigen assay (S-ICT test) to be $84.5 \%, 96.2 \%, 95.6 \%, 86.4 \%$, and $90.4 \%$, respectively ${ }^{23}$. However, these results differ from the findings of a study performed in Turkey by Korkmaz et al. $(2015)^{21}$. They reported the sensitivity, specificity, PPV, NPV, and accuracy of an immunochromatographic HpSAg test as 51.6\%, 96\%, 88.8\%, 76.1\% and $79 \%$, respectively. Lower sensitivities for HpSAg tests have occurred in special circumstances, such as those undergoing proton pump inhibitor (PPI) or bismuth therapy, patients with liver cirrhosis, and patients with hidden gastrointestinal bleeding ${ }^{23}$ which may have resulted in a false-negative HpSAg test. Nonetheless, the low colonization of bacteria in the stomach and the consequent low concentrations of $H$. pylori antigen in the feces could be sufficient enough to cause false-negative results ${ }^{21}$.

\section{CONCLUSION}

The HpSAg test can be a reliable alternative to the other techniques used to diagnose active $H$. pylori infection. This test can also be utilized in some special circumstances, such as when an endoscopy is not available. However, due to the limited number of patients in this study, a larger investigation with a larger number of peptic ulcer patients is required to support the conclusions of this study. Overall, the HpSAg test is a sustainable alternative to invasive tests for the detection of $H$. pylori infection in children, especially in developing countries such as Bangladesh where the prevalence of infection is very high. The test may also be used to monitor the therapeutic response to $H$. $p y$ lori infection.

\section{ABBREVIATIONS}

CMCH: Chattogram Medical College and Hospital

GI: Gastrointestinal

HpSAg: H. pylori Stool Antigen

ICT: Immunochromatograpic Test

MD: Microscopic Detection

NPV: Negative Predictive Value

PPV: Positive Predictive Value

PUD: Peptic Ulcer Disease

RUT: Rapid Urease Test

\section{ACKNOWLEDGMENTS}

Department of Microbiology and Virology, Chittagong Medical College, Chattogram, Bangladesh. Department of Medicine, Chittagong Medical College, Chattogram, Bangladesh.

\section{AUTHOR'S CONTRIBUTIONS}

Afreen Sultana: Study design, data collection, data analysis, data visualization, manuscript writing; Shakeel Ahmed: Supervision; Ershad Uddin Ahmed: Study design, supervision; Abul Faisal MD. Nuruddin Chowdhury: Study design, data analysis; Abul Kalam: Data collection; Arifur Rahman: Data collection; Farhana Akter: Manuscript writing and editing; A. H. M. Saiful Karim Chowdhury: Data collection; Sabrina Sharmin: Data collection; Jannatul Ferdous Mustry: Data collection; Ayan Saha: Study design, supervision, data analysis, data visualization. All authors read and approved the final manuscript.

\section{FUNDING}

None.

\section{AVAILABILITY OF DATA AND MATERIALS}

Data and materials used and/or analyzed during the current study are available from the corresponding author on reasonable request.

\section{ETHICS APPROVAL AND CONSENT TO PARTICIPATE}

This study was conducted in accordance with the amended Declaration of Helsinki. The Ethical committee of Chittagong medical college approved (Ref: CMC/PG/2018/379) the study, and all participants provided written informed consent.

\section{CONSENT FOR PUBLICATION}

Not applicable.

\section{COMPETING INTERESTS}

The authors declare that they have no competing interests.

\section{REFERENCES}

1. Crowe SE. Helicobacter pylori Infection. The New England Journal of Medicine. 2019;380(12):1158-65. PMID: 30893536. Available from: 10.1056/NEJMcp1710945.

2. Suerbaum $S$, Michetti P. Helicobacter pylori infection. The New England Journal of Medicine. 2002;347(15):1175-86. PMID: 12374879. Available from: 10.1056/NEJMra020542.

3. Ahmad MM, Rahman M, Rumi AK, Islam S, Huq F, Chowdhury $M F$, et al. Prevalence of Helicobacter pylori in asymptomatic population: a pilot serological study in Bangladesh. Journal of Epidemiology. 1997;7(4):251-4. PMID: 9465552. Available from: 10.2188/jea.7.251.

4. Mahalanabis D, Rahman MM, Sarker SA, Bardhan PK, Hildebrand $P$, Beglinger $C$. Helicobacter pylori infection in the young in Bangladesh: prevalence, socioeconomic and nutritional aspects. International Journal of Epidemiology. 1996;25(4):894-8. PMID: 8921472. Available from: 10.1093/ ije/25.4.894. 
5. Graham DY, Adam E, Reddy GT, Agarwal JP, Agarwal R, Evans DJ. Seroepidemiology of Helicobacter pylori infection in India. Comparison of developing and developed countries. Digestive Diseases and Sciences. 1991;36(8):1084-8. PMID: 1864201. Available from: 10.1007/BF01297451.

6. Everhart JE, Kruszon-Moran D, Perez-Perez GI, Tralka TS, McQuillan G. Seroprevalence and ethnic differences in Helicobacter pylori infection among adults in the United States. The Journal of Infectious Diseases. 2000;181(4):135963. PMID: 10762567 . Available from: 10.1086/315384.

7. Andersen LP, Rosenstock SJ, Bonnevie O, Jørgensen T. Seroprevalence of immunoglobulin $\mathrm{G}, \mathrm{M}$, and $\mathrm{A}$ antibodies to Helicobacter pylori in an unselected Danish population. American Journal of Epidemiology. 1996;143(11):1157-64. PMID 8633606. Available from: 10.1093/oxfordjournals.aje.a008694.

8. Rahman MM, Rowshon A, Rahim S. Diagnosis of Helicobactor pylori in Bangladesh: limited options and utility of serologic test. Journal of Shaheed Suhrawardy Medical College. 2013;5(1):1-2. Available from: 10.3329/jssmc.v5i1.16195.

9. Moayyedi P, Deeks J, Talley NJ, Delaney B, Forman D. An update of the Cochrane systematic review of Helicobacter pylori eradication therapy in nonulcer dyspepsia: resolving the discrepancy between systematic reviews. The American Journal of Gastroenterology. 2003;98(12):2621-6. PMID: 14687807. Available from: 10.1111/j.1572-0241.2003.08724.x.

10. Miftahussurur M, Yamaoka Y. Diagnostic methods of Helicobacter pylori infection for epidemiological studies: critical importance of indirect test validation. BioMed Research International. 2016;2016:4819423. PMID: 26904678. Available from: $10.1155 / 2016 / 4819423$.

11. Howden CW, Hunt RH, on Practice Parameters of the American College of Gastroenterology AHC. Guidelines for the management of Helicobacter pylori infection. The American Journal of Gastroenterology. 1998;93(12):2330-8. PMID: 9860388. Available from: 10.1111/j.1572-0241.1998.00684.x.

12. Ansari S, Yamaoka Y. Current understanding and management of Helicobacter pylori infection: an updated appraisal. F1000 Research. 2018;7:7. PMID: 29946428. Available from: 10.12688/f1000research.14149.1.

13. Khatoon J, Rai RP, Prasad KN. Role of Helicobacter pylori in gastric cancer: updates. World Journal of Gastrointestinal Oncology. 2016;8(2):147-58. PMID: 26909129. Available from: 10.4251/wjgo.v8.i2.147.

14. Gulcan EM, Varol A, Kutlu T, Cullu F, Erkan T, Adal E. Helicobacter pylori stool antigen test. Indian Journal of Pediatrics. 2005;72(8):675-8. PMID: 16131773. Available from:
10.1007/BF02724076.

15. Alam MR, Ahmed E, Rahman MZ, Islam A, Khan MM, Ahmed D. A study on healing of peptic ulcer disease after eradication of Helicobacter pylori infection. Bangladesh Medical Journal. 2014;43(2):84-9. Available from: 10.3329/bmj.v43i2.21388.

16. Islam M, Rahman S, Shamsuzzaman S, Muazzam N, Kibria S, Hossain M. A comparative study among different invasive methods for the diagnosis of Helicobacter pylori. Faridpur Medical College Journal. 2010;5(1):21-4. Available from: 10 . 3329/fmcj.v5il.6809.

17. Ghosh CK, Khan MR, Alam F, Shil BC, Kabir MS, Mahmuduzzaman M. Peptic ulcer disease in Bangladesh: A multi-centre study. Mymensingh medical journal. Mymensingh Medical Journal. 2017;26(1):141-4. PMID: 28260768.

18. Garg B, Sandhu V, Sood N, Sood A, Malhotra V. Histopathological analysis of chronic gastritis and correlation of pathological features with each other and with endoscopic findings. Polish journal of pathology : official journal of the Polish Society of Pathologists. 2012;63(3):172-178. Available from: 10.5114/pjp.2012.31501.

19. Basir HRG, Ghobakhlou M, Akbari P, Dehghan A, Rabiei MAS Correlation between the intensity of Helicobacter pylori colonization and severity of gastritis. Gastroenterology Research and Practice. 2017;2017:8320496. PMID: 29317866. Available from: 10.1155/2017/8320496.

20. Waidyarthne E, Mudduwa L, Lekamwasam J, Lekamwasam S. Helicobacter pylori detection techniques: comparison of sensitivity, specificity and cost. Galen Medical Journal. 2012;17(2):1. Available from: 10.4038/gmj.v17i2.4900.

21. Korkmaz H, Findik D, Ugurluoglu C, Terzi Y. Reliability of stool antigen tests: investigation of the diagnostic value of a new immunochromatographic Helicobacter pylori approach in dyspeptic patients. Asian Pacific Journal of Cancer Prevention. 2015;16(2):657-60. PMID: 25684503. Available from 10.7314/APJCP.2015.16.2.657.

22. Osman HA, Hasan H, Suppian R, Bahar N, Hussin NS, Rahim AA. Evaluation of the Atlas Helicobacter pylori stool antigen test for diagnosis of infection in adult patients. Asian Pacific Journal of Cancer Prevention. 2014;15(13):5245-7. PMID: 25040982. Available from: 10.7314/APJCP.2014.15.13.5245.

23. Jekarl DW, An YJ, Lee S, Lee J, Kim Y, Park YJ. Evaluation of a newly developed rapid stool antigen test using an immunochromatographic assay to detect Helicobacter pylori. Japanese Journal of Infectious Diseases. 2013;66(1):60-4 PMID: 23429088. Available from: 10.7883/yoken.66.60. 
Ready to submit your manuscript? Choose Biomedpress and benefit from:

- Fast, convenient online submission

- Through peer-review by experienced researchers

- Rapid publication on acceptance

- Free of charge (without publication fees)

Learn more http://www.biomedpress.org/journals/
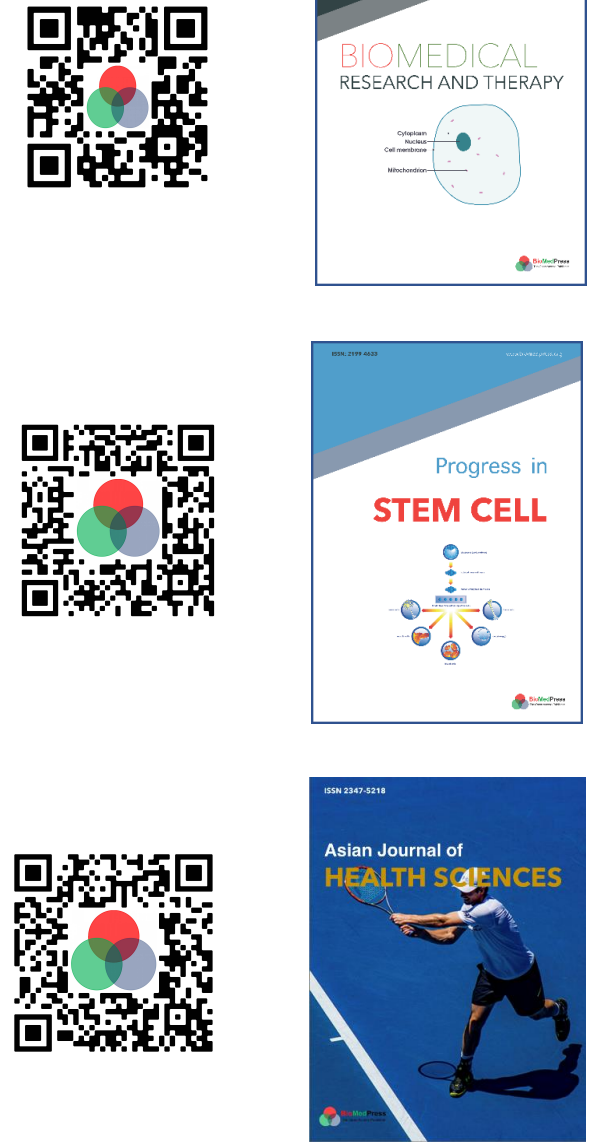

Asian Journal of Health Sciences

ISSN: 2347-5218

Indexed: Google Scholar

Acceptance Rate (2020): 72.89\%

Article Publishing Charge: Free

Submission to first editorial decision: 16.5 days

Biotechnological Research

ISSN: 2395-6763

Indexed: Google Scholar

Acceptance Rate (2020): $67.02 \%$

Article Publishing Charge: Free

Submission to first editorial decision: 28.5 days 